\title{
AMAMENTAÇÃO NA PRIMEIRA HORA DE VIDA E A CONTINUIDADE DO ALEITAMENTO EXCLUSIVO ATÉ OS 40 DIAS
}

\author{
Erika Zambrano Tanaka ${ }^{1}$, Monica Borges de Freitas Valério ${ }^{1}$, Joana Zambrano Chambrone ${ }^{2}$ \\ ${ }^{1}$ Faculdade Anhanguera, Curso de Enfermagem, Bauru, SP. ${ }^{2}$ Universidade Estadual Paulista - UNESP, Programa de Pós Graduação \\ em Fisioterapia, Presidente Prudente, SP. e-mail: jo chambrone@hotmail.com
}

\section{RESUMO}

A promoção do aleitamento materno deve ser vista como uma ação importante para a vida de um recém-nascido e sua família. Os objetivos foram verificar a amamentação na primeira hora de vida e a continuidade desse aleitamento exclusivo até os 40 dias, identificar se as puérperas realizaram o pré-natal e se foram orientadas quanto ao aleitamento. Tratou-se de uma pesquisa descritiva. Os dados foram coletados numa maternidade em Bauru-SP, envolveu 20 puérperas, com idade mínima de 18 anos, com aprovação do Comitê de Ética (699.586/2014). Foi observado que 20 (100\%) realizaram o pré-natal e 6 (30\%) receberam informações sobre aleitamento materno no pré-natal; 17 (85\%) amamentaram seus filhos na primeira hora de vida. Após 40 dias, das 17 (85\%) que amamentaram na primeira hora de vida, 15 (75\%) continuam amamentando de modo exclusivo, 2 (10\%) amamentam com leite materno e complemento, 1 (5\%) interrompeu o aleitamento, 17 (85\%) estão satisfeitas em amamentar.

Palavras-chave: aleitamento materno, cuidado pré-natal, período pós-parto.

\section{BREASTFEEDING IN THE FIRST HOUR OF LIFE AND THE CONTINUATION OF EXCLUSIVE BREASTFEEDING UP TO 40 DAYS}

\section{ABSTRACT}

The promotion of breastfeeding should be seen as an important action for the life of a newborn and his family. The objective was to verify breastfeeding in the first hour of life and the continuity of exclusive breastfeeding up to 40 days, to identify whether the mothers had prenatal and if she was oriented on breastfeeding. This was a descriptive research. Data were collected in a maternity Bauru-SP, involved 20 mothers, aged at least 18 years, with the approval of the Ethics Committee (699.586/2014). It was observed that 20 (100\%) underwent prenatal and 6 (30\%) received information about breastfeeding during prenatal care; 17 (85\%) breastfed their children in the first hour of life. After 40 days, the 17 (85\%) who breastfed in the first hour of life, 15 (75\%) still breastfeeding exclusively, 2 (10\%) nursing with breast milk and supplement, 1 (5\%) stopped breastfeeding, 17 (85\%) are satisfied in nursing.

Keywords: breast feeding, prenatal care, postpartum period.

\section{INTRODUÇÃO}

O leite materno é o alimento ideal para o lactente, sendo o mais completo em nutrientes e anticorpos. Ele oferece vantagens para o bebê, para a mãe, família e para o Estado. Para o bebê fornece água, vitaminas, minerais, ferro, lactose, proteínas e gordura, além de efeito protetor contra infecções como diarreia, pneumonia, infecção urinária e de ouvido, doenças alérgicas e autoimunes como eczemas, bronquite e diabetes. Obtêm um melhor desenvolvimento neuropsicomotor, emocional e em testes de Inteligência, melhor resposta a vacinação e menor risco de desenvolver doenças crônicas como hipertensão e obesidade ${ }^{1}$. Ele é de fácil digestão, além de ajudar na excreção do mecônio ${ }^{2}$.
Segundo King $^{3}$ essa proteção contra infeções ocorre devido ao leite materno ser estéril e conter imunoglobulinas e lactoferrina que vai proteger o bebê até que ele comece a produzir seus próprios anticorpos.

Para a mãe reduz o sangramento após o parto, protege contra uma nova gravidez se esse for exclusivo, menor risco de câncer de mama e de ovário, menor incidência de depressão pósparto, perda mais rápida do peso, reduz risco de artrite reumatoide, além de estabelecer um vínculo de amor e carinho mãe-filho ${ }^{4}$.

Para a família está relacionado com o custo e praticidade. Não precisa sair de casa para comprar e economiza muito comparado com os leites formulados. Para o Estado é de baixo custo e reduz o índice de mortalidade infantil ${ }^{1}$. 
Por se tratar de uma prática fundamental para promoção, proteção e apoio à saúde da criança, a Organização Mundial da Saúde (OMS) e Ministério da Saúde (MS) junto com o Fundo das Nações Unidas para a Infância (UNICEF) propuseram a Iniciativa Hospital Amigo da Criança (IHAC), cujo objetivo é garantir apoio total à puérpera e o sucesso do aleitamento materno. Segundo OMS e MS o recém-nascido (RN) deve receber o leite materno dentre a primeira hora de vida, perdurando os primeiros seis meses de modo exclusivo e continuar até dois anos ou mais junto com complementos correto $^{1}$.

O leite humano possui propriedades próprias nos quais o recém-nascido precisa recebê-lo por completo, por isso a importância de estimular a mãe a fornecer o colostro que é o leite produzido nos primeiros dias pós-parto. Com coloração amarelada, seu volume oscila de 2 a $20 \mathrm{ml}$ por mamada, sua duração do período vária muito, porem alguns estudiosos consideram até o quinto dia pós-parto, ele é perfeitamente adequado ao recém-nascido, pois é produzido em baixa quantidade justamente porque o bebê ainda não está com os rins totalmente preparados para processar grande volume de líquido 5 .

A modificação de sua composição ocorre de forma gradual, passando para o "leite de transição", aquele produzido entre o colostro e o leite maduro. Posteriormente o "leite maduro" tendo o anterior, aquele do inicio da mamada rico em proteínas, lactose, vitaminas, minerais e água; depois o leite posterior do final da mamada, rico em gordura ${ }^{5}$.

Quando analisamos o fator de proteção que o leite humano trás para o recém-nascido questionamos do porque os números de mortes de bebês no período neonatal continuam a crescer. Estimativas mostram que a cada ano, mais de quatro milhões de bebês morrem nesses primeiros 27 dias de vida 6 .

Diante disso, os enfermeiros e outros profissionais da saúde devem incentivar o aleitamento materno e apoiar as mães para inicia-lo o mais precocemente, dando orientações no pré-natal e empoderando essas mães a amamentaram ainda na sala de parto ${ }^{2}$.

O contato pele a pele com a mãe imediatamente após o nascimento proporciona uma tranquilidade para a mãe e bebê incomparável. Ajudar as mães para esse início do aleitamento materno corresponde ao quarto passo da Iniciativa Hospital Amigo da Criança (IHAC). Sendo essa uma prática que pode reduzir em $22 \%$ a mortalidade neonatal, quando mais se prorroga o início do aleitamento mais chances de morte por infecção ${ }^{6}$.

Dentre os profissionais da saúde que podem realizar essa aproximação, destaca-se o enfermeiro, por estar mais próximo da puérpera e do recém-nascido nos diferentes níveis de atenção à saúde. Assim, entende-se que a enfermagem pode ser um agente de mudanças, valorizar a decisão e sentimentos das mães, assumindo um papel normatizador e regulador do aleitamento materno, agindo com ética e respeitando o binômio mãe-filho, sempre pautado num saber científico ${ }^{7}$.

A amamentação na primeira hora de vida segundo a OMS deve ser implementada como rotina hospitalar, pois é evidente que essa aproximação precoce predispõe um aleitamento natural e desejado. Assim, o objetivo deste estudo será conhecer o significado da vivência da mãe quanto à amamentação na primeira hora de vida, verificar a continuidade desse aleitamento exclusivo até os 40 dias, e também identificar se as puérperas realizaram o pré-natal e se foram orientadas quanto ao aleitamento.

\section{MATERIAL E MÉTODOS}

Este estudo trata-se de uma pesquisa descritiva. Participaram da amostra 20 gestantes de 18 anos ou mais, residentes no município de Bauru e que tiveram parto normal no mês de setembro/2014.

As voluntárias responderam um questionário formulado pelas pesquisadoras, este contemplava perguntas como: idade, estado civil, quantidade de filhos, realização do pré-natal, informações sobre aleitamento no pré-natal, pretensão em amamentar até os seis meses de modo exclusivo, a importância do aleitamento materno para as mães.

Após 40 dias foi usado um segundo questionário onde contemplava perguntas como: eficácia do aleitamento materno após 40 dias, satisfação com o ato de amamentar e se precisou de ajuda para amamentar de algum profissional da saúde ou do Banco de Leite.

O estudo teve aprovação do Comitê de Ética (699.586/2014) e todas as voluntárias que aceitaram participar da pesquisa assinaram 0 Termo de Consentimento Livre e Esclarecido. 
A análise descritiva contou com a revisão de literatura baseada na consulta de artigos científicos. Para a análise dos dados foi utilizado o software MS Excel 2010 para a elaboração das tabelas e gráficos. Os resultados foram apresentados mediantes as informações colhidas nas abordagens.

\section{RESULTADOS}

A Tabela 1 descreve a população de estudo. A maioria apresentou idades variadas, situando-se na média de 26 anos.

Tabela 1. Características gerais das puérperas.

\begin{tabular}{lcc}
\hline Características & Freq. & $\%$ \\
\hline Idade de 18 a 24 anos & 11 & 55 \\
Idade 25 a 30 anos & 4 & 20 \\
Idade superior a 30 anos & 5 & 25 \\
Casadas & 8 & 40 \\
Solteiras & 9 & 45 \\
União Estável & 3 & 15 \\
Primigestas & 8 & 40 \\
Multigesta & 12 & 60 \\
TOTAL & 20 & 100 \\
\hline
\end{tabular}

A Tabela 2 apresenta as respostas das mães do questionário aplicado após o nascimento. Contêm dados sobre o pré e pós- natal. Todas as mulheres relataram ter feito o pré-natal, porÉm somente 6 (30\%) receberam informações sobre o aleitamento materno no mesmo.

Tabela 2. Questionário após o nascimento.

\begin{tabular}{lcc}
\hline Variáveis & Freq. & $\%$ \\
\hline Realizou o pré-natal & 20 & 100 \\
$\begin{array}{l}\text { Recebeu informações sobre aleitamento } \\
\text { materno no pré-natal }\end{array}$ & 6 & 30 \\
$\begin{array}{l}\text { Foi realizado o Aleitamento Materno na } \\
\text { primeira hora de vida }\end{array}$ & 17 & 85 \\
$\begin{array}{l}\text { Pretende amamentar até os seis meses } \\
\text { de modo exclusivo }\end{array}$ & 19 & 95 \\
TOTAL & 20 & 100 \\
\hline
\end{tabular}

Na Figura 1 apresentamos as respostas das mães em relação à importância do aleitamento materno. Observamos que, segundo o seu conhecimento, para elas receber nutrientes é o mais importante em relação ao ato de amamentar.

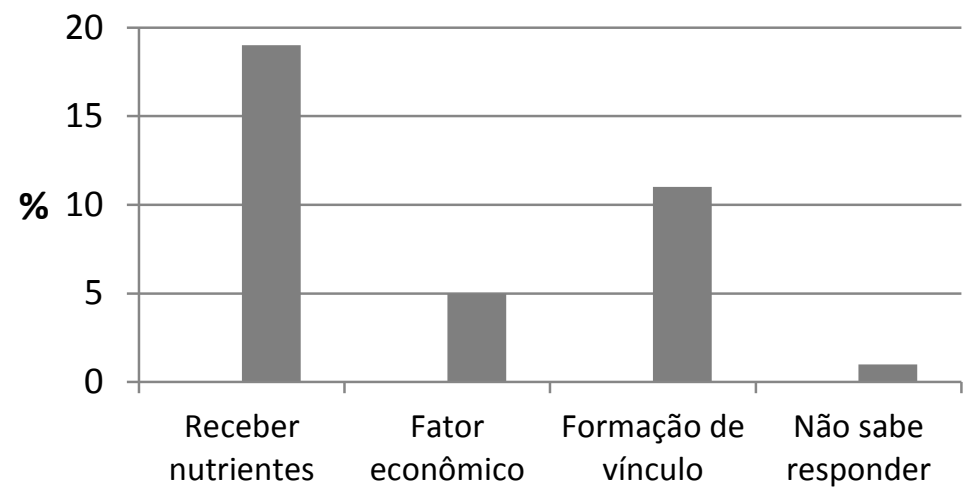

Figura 1. Importância para a puérpera em relação ao aleitamento materno.

Após 40 dias as puérperas foram questionadas quanto à eficácia do aleitamento materno diante da vida do bebê. Como mostra na Tabela 3, a maioria das mães que amamentaram na primeira hora de vida permanecem em aleitamento exclusivo após 40 dias, 17 (85\%) verbalizaram satisfação em amamentar e somente $5(25 \%)$ precisou procurar ajuda para amamentar. 
Tabela 3. Questionário após 40 dias.

\begin{tabular}{|c|c|c|}
\hline Variáveis & $\mathrm{N}$ & $\%$ \\
\hline $\begin{array}{l}\text { Amamentação eficaz exclusivo dentro } \\
\text { dos } 40 \text { dias }\end{array}$ & 15 & 75 \\
\hline $\begin{array}{l}\text { Amamentação e uso de complemento } \\
\text { dentro dos } 40 \text { dias }\end{array}$ & 2 & 10 \\
\hline Amamentação interrompida & 1 & 5 \\
\hline $\begin{array}{l}\text { Puérperas que não conseguimos contato } \\
\text { após } 40 \text { dias }\end{array}$ & 2 & 10 \\
\hline $\begin{array}{l}\text { Criança está satisfeita após a mamar no } \\
\text { peito }\end{array}$ & 15 & 75 \\
\hline $\begin{array}{l}\text { Verbalização materna de satisfação por } \\
\text { amamentar }\end{array}$ & 17 & 85 \\
\hline $\begin{array}{l}\text { Procurou ajuda para conseguir } \\
\text { amamentar nesses } 40 \text { dias }\end{array}$ & 5 & 25 \\
\hline TOTAL & 20 & 100 \\
\hline
\end{tabular}

Foi encontrada uma relação entre a amamentação na primeira hora de vida e a continuidade até os 40 dias de modo exclusivo. Ao se analisar o gráfico de pizza (Figura 2), observou-se que, (85\%) das mães que amamentaram logo após o nascimento se sentiram mais confiantes e capazes de realizar o aleitamento de forma natural em sua casa. Destas (75\%) permanecem em aleitamento exclusivo e as outras (10\%) estão amamentando com leite materno mais complemento por indicação médica. As mesmas afirmaram que o ato de amamentar seus filhos logo após o nascimento favorece na descida do leite, sendo um dos fatores mais decorrentes do desmame precoce.

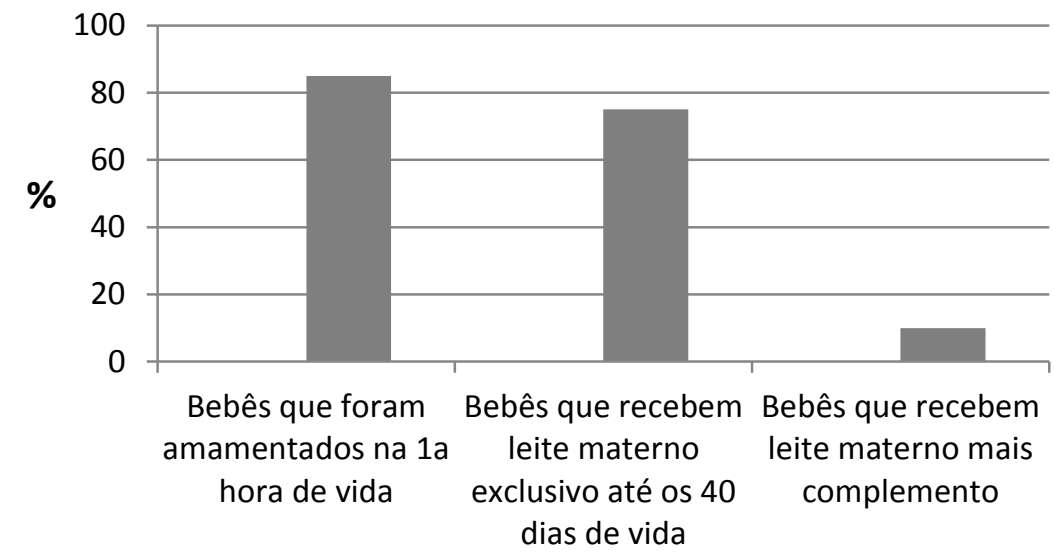

Figura 2. Recém-nascidos que foram amamentados.

\section{DISCUSSÃO}

O objetivo deste estudo era conhecer o significado da vivência da mãe quanto à amamentação na primeira hora de vida, verificar a continuidade desse aleitamento exclusivo até os 40 dias, e também identificar se as puérperas realizaram o pré-natal e se foram orientadas quanto ao aleitamento.

Como mostra a Tabela 2, todas as mulheres relataram ter feito o pré-natal, porem somente $6(30 \%)$ receberam informações sobre o aleitamento materno no mesmo. A decisão de amamentar ou não o bebê ocorre, na grande maioria das vezes, bem antes do parto. Desta forma orientações no pré-natal sobre a importância desse ato influencia tanto o início quanto a extensão do aleitamento ${ }^{8}$.
A orientação pré-natal deve abordar a interferência de alimentos artificiais, do uso de bicos de mamadeiras e de chupetas, a prática de livre demanda e do início na primeira hora de vida e do alojamento conjunto. Estas práticas têm impacto sobre a prevalência de aleitamento materno exclusivo e sobre a satisfação das gestantes e mães com o apoio recebido para amamentar ${ }^{9}$.

A pergunta norteadora no qual se diz respeito à amamentação na primeira hora de vida, foi considerada amamentação na primeira hora de vida o oferecimento do peito em até sessenta minutos a partir do nascimento e 17 (85\%) das puérperas relataram ter amamentado seus filhos logo após o nascimento.

De acordo com os dados levantados, pode se perceber que colocar o bebê em contato 
pele a pele com a mãe e estimular a amamentação na primeira hora de vida influencia no desejo das mães em continuar amamentando, pois esse contato faz com que a puérpera tenha confiança de que isso vai ocorrer mais naturalmente nos momentos posteriores.

\section{CONCLUSÃO}

Assim, o resultado mostrou uma inteira relação entre bebês amamentados na primeira hora de vida e a continuidade desse aleitamento de modo exclusivo dentro dos quarenta dias de vida. Desta forma, acreditamos que todas as instituições devam investir nessa prática e que esse incentivo deva começar no pré-natal para que as mães sejam empoderadas a amamentar ainda na sala de parto.

Uma das formas de ajudar ainda mais as mães é a capacitação profissional. É necessário que os profissionais desenvolvam competências e habilidades em aleitamento materno para realizar intervenções adequadas e superar as possíveis barreiras à amamentação, sobretudo na sala de parto.

\section{CONFLITO DE INTERESSE}

Os autores declaram não haver qualquer potencial de conflito de interesse que possa interferir na imparcialidade deste trabalho científico.

\section{REFERÊNCIAS}

1. Marques ES, Cotta RMM, Priore SE. Mitos e crenças sobre o aleitamento materno. Ciênc Saúde Col. 2011; 16(5):2461-8. DOI: http://dx.doi.org/10.1590/S141381232011000500015 .

2. Silva EP, Alves AR, Macedo ARM, Bezerra RMSB, Almeida PC, Chaves EMC. Diagnósticos de enfermagem relacionados à amamentação em unidade de alojamento conjunto. Rev Bras Enferm. 2013;66(2):190-5. DOI: http://dx.doi.org/10.1590/S003471672013000200006 .

3. King FS. Como ajudar as mães a amamentar. 4.ed. Brasília: Ministério da Saúde, 2001.

4. Sampaio PF, Moraes CL, Reichenheim ME, Oliveira ASD, Lobato G. Nascer em Hospital Amigo da Criança no Rio de Janeiro, Brasil: um fator de proteção ao aleitamento materno? Cad Saúde Pública. 2011;27(7):1349-61. DOI:
5. Castro DA. Amamentação na primeira hora pósparto: vivência de mulheres em parto domiciliar e hospitalar, 2010. 71 f. [Monografia]. Curso de Enfermagem. Universidade Estadual de Feira de Santana, 2010.

6. Boccolini CS, Carvalho ML, Oliveira MIC, PérezEscamilla R. A amamentação na primeira hora de vida e mortalidade neonatal. J Pediatr. 2013;89(2):131-6. DOI: http://dx.doi.org/10.1016/i.jped.2013.03.005.

7. Barbosa $V$ et al. Aleitamento Materno na sala de parto: a vivência da puérpera. Ciênc Cuid Saúde. 2010;9(2):366-73.

DOI: http://dx.doi.org/10.4025/cienccuidsaude.v9i2.11249 8. Donath SM, Amir LH. Alspac Study Team. Relationship between prenatal infant feeding intention and initiations and duration of breastfeeding: a cohort study. Acta Paediatr. 2003;92:352-6.

9. Nascimento VC, Oliveira MIC, Alves VH, Silva KS. Associação entre as orientações pré-natais em aleitamento materno e a satisfação com o apoio para amamentar. Rev Bras Saúde Mater Infant. 2013;13(2):147-59. DOI: http://dx.doi.org/10.1590/S1519$\underline{38292013000200008}$

Recebido para publicação em 28/08/2015

Revisado em 18/09/2015

Aceito em 22/09/2015

http://dx.doi.org/10.1590/S0102-

$\underline{311 \times 2011000700010}$ 